\title{
Moving Toward A Digital Competency-based Approach in Applied Education: Developing a System Supported by Blockchain to Enhance Competency-Based Credentials
}

\author{
Ahmed Ghonim ${ }^{1,2} \&$ Irene Corpuz $^{1}$ \\ ${ }^{1}$ Higher Colleges of Technology, United Arab Emirates \\ ${ }^{2}$ The Higher Institute of Applied Arts, Egypt \\ Correspondence: Ahmed Ghonim, Higher Colleges of Technology, P.O. Box: 25026, Abu Dhabi, United Arab \\ Emirates.
}

Received: February 18, 2021

Accepted: April 4, 2021

Online Published: April 8, 2021

doi:10.5430/ijhe.v10n5p33

URL: https://doi.org/10.5430/ijhe.v10n5p33

\begin{abstract}
A competency-based approach to education (CBE) has emerged in recent years, fostering curriculum by tracking and indicting students' acquired skills and competencies. Since applied education is moving away from a theoretical approach to its application, employers are eager to be empowered with graduates' full e-profiles, which demonstrate candidates' competency-based strengths and weaknesses. This study considered a new digital system for competency-based learning, enhanced by Blockchain and badge technologies, to improve and indicate practical classes' quality in applied programs. Our core objectives were to promote the digitalization of competency-based education and students' e-portfolios as a proposed system in applied education. We also assessed its implementation, beginning with a learning gap analysis and moving on to discuss the digital CBE to support employers' ability to validate graduates' competency-based credentials acquired through their signature learning experience. We found that the digitalization of skills and competency-based credentials should be enhanced to foster knowing-by-doing and practical capabilities, which should be incorporated in applied education to achieve optimum CBE results and support recruitment and professional development processes.

Further research and study are recommended to develop and unify standards adopted by the Higher Education Institutions (HEIs), that are recognized by the industries.
\end{abstract}

Keywords: competency-based education, signature learning experience, outcome-based approach, e-portfolio, blockchain in education, learning experience outcomes

\section{Introduction}

This paper argues that the competency-based education (CBE) approach fits the nature of applied education and can be integrated successfully. There is an urgent need to match industry expectations with the learning experience and provide new micro-credentials to identify the level of acquired skills and competencies.

We must gradually move toward developing competency micro-credentials that are relevant in the workplace to quickly identify the gaps between the skills graduates have been equipped with during their study against the skills that are needed in alignment with the new trends of industry for economic development and expansion (World Economic Forum, New Vision for Education, 2015).

A new e-system, which utilizes novel Blockchain technologies, is proposed to present the strengths and weaknesses of the desired skills and competencies by assessing practical activities as an outcome of a signature learning experience.

\section{Method}

\subsection{Literature Review}

\subsubsection{Competency-Based Approach in Applied Education}

Historical studies in higher education trace the use CBE back to the Morrill Land Acts of 1862, which provided the basis for applied education (Clark FW, 1976). As the industrial revolution brought various types of more advanced and complicated machinery, higher-education institutions provided learners the opportunities to be doers rather than thinkers as had been prevalent in the ages before (Perkin H., 2007). These programs relied less on rote teaching and 
learning experience than contemporary academic programs. They focused more on practical training, where students could apply what they learned in pragmatic job situations (Goodchild L., 2007).

Progressive education movements, which go back 60 years or more, introduced the philosophy of CBE as an approach for learning professional skills, rather than abstract traditional learning approaches (Carraccio et al., 2002; Grant et al., 1979; Spady WG, 1977). CBE has been described in higher education as a form of "problem-based learning," "mastery-based learning," "outcome-based learning," and "performance-based learning." However, all these terms fail to wholly capture the essence of CBE (Gervais J., 2016), and there is a lack of evidence concerning the acquiring of skills and competencies against industry expectations. CBE applications should differ from the contemporary higher education model, wherein students are evaluated based on their individual competencies and transition into more complex competencies assessment once they have mastered a skill through relevant activities.

CBE has been defined in multiple ways and diversely interpreted across academic programs. Spady WG (1977) defined CBE as "a data-based, adaptive, performance-oriented set of integrated processes that facilitate, measure, record, and certify within the context of flexible time parameters the demonstration of known, explicitly stated, and agreed-upon learning outcomes that reflect successful functioning in life roles" (Spady WG, 1977, p. 10, as cited in J. Gervais, 2016).

Kelchen R. (2015) defined CBE as a form of higher education in which credit is provided based on attaining learning skills - through competency instead of credit or clock hours of teaching the theories Kelchen R. (2015). Gervais J. (2016) defined CBE as an outcome-based approach in the education setting that incorporates modes of instructional activities delivery and assessment efforts that are designed to evaluate the mastery of students' learning experience through their demonstration of the knowledge, attitudes, values, skills, and behaviors required for the sought degree instead of regular credit hours (Gervais J., 2016).

Also, CBE can be defined as a nontraditional learning model based on students' ability to demonstrate attainment of defined competencies at a desired level of achievement through some form of activity assessment (Kelchen R., 2015; Klein-Collins R., 2012)

The differences among these definitions of CBE tend to be related to the role that they happen to occupy in their industry. Instructional professionals understand $\mathrm{CBE}$ as a student-centered learning approach explicitly tailored to each student's needs and their aspiring professional role.

The proposed definition for CBE in applied education is as follows: It is a learning experience approach that determines the framework for skills and competencies, which will be utilized as a base for construction, implementation, assessment, and evaluation of applied education programs-expanded with updated detailed learning experience outcomes (LEOS)—that identifies the level of each skill and competency acquired during the learning journey.

\subsubsection{Technological Applications in CBE}

Previously, technology providers did not aggressively pay attention to the different features required to manage the conceptual component of the CBE process (Leuba M., 2015). Currently, the technology providers have matured—not only to develop a secured application but also to ensure the alignment to the learning technology interoperability standards set by the IMS Global Learning Consortium (http://www.imsglobal.org/). IMS Global has established a clear direction toward effective information-technology support for CBE.

In January 2020, Gartner published a paper: Assessing Online Learning Platforms for Technical Skills Development. It describes the characteristics of effective online learning platforms, which could include the technologies enabling CBE. These characteristics include engaging user experience, personalized recommendations, tailored learning paths, multimedia content, enterprise integration, artificial intelligence (AI) capabilities, gamified interaction, and social learning (Gartner, 2020). Online CBE marks the critical convergence of multiple vectors of the right learning model, the right technologies, the right customers, and the right business model (Weise, 2014).

The use of CBE in the Fourth Industrial Revolution requires adopting and applying innovation and technology (Ally M., 2019). Enabling technologies such as AI and the Internet of Things - coupled with business intelligence, learning portals, and dashboards to support universities and higher-education entities-fosters the production of highly competent and qualified knowledge workers through the CBE system. Blockchain has been used in the education industry for the issuance of digital degrees and micro-credentials, which enables the students to share with the employers their education credentials with ease, and enabling the employers to do online verification (Williams P., 2018). These credentials could include a letter of completion, course transcript, or degree. 
Applied higher educations have invested in implementing a CBE system that focuses on 21st-century skills and applied strategic interventions to make its students and graduates more accessible to employers and build a culture of life-long learning through CBE. Hence, now is the time to support these strategies and educational approaches with technology enablers that will enhance applied education delivery and ensure transparency in achieving Learning Experience Outcomes (LEOs), which are the employers' primary target. (World Economic Forum, New Vision for Education, 2015).

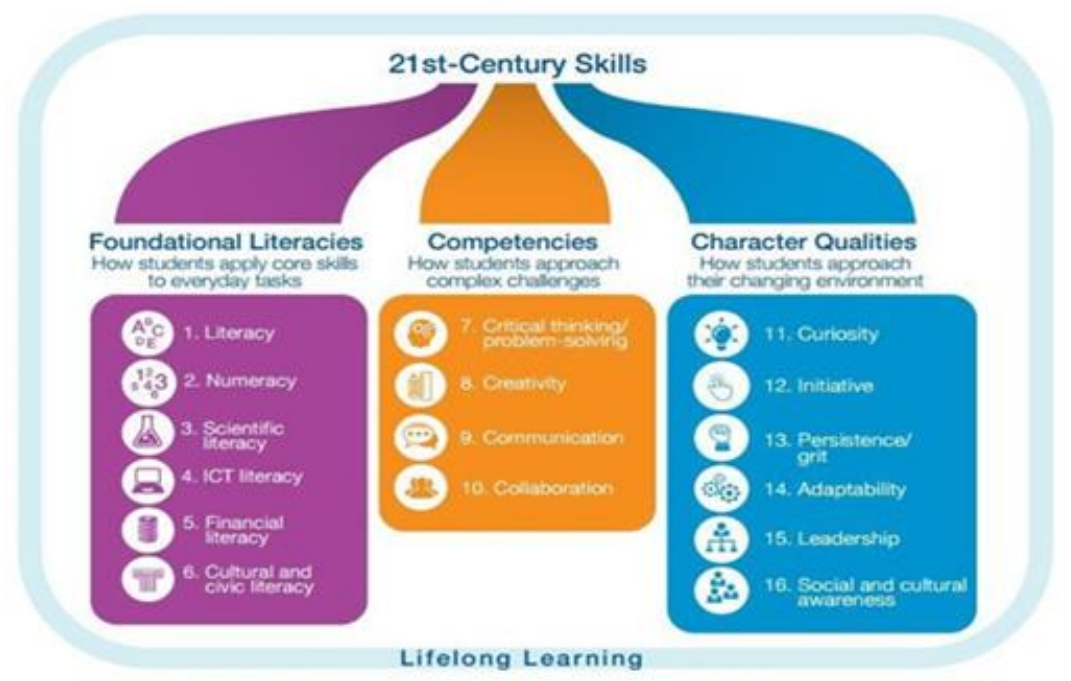

Figure 1.21st Century Skills

Source: https://www.weforum.org/agenda/2016/03/21st-century-skills-future-jobs-students/

\subsubsection{Blockchain Technology}

Blockchain was first perceived by Satoshi Nakamoto as a peer-to-peer money exchange system. From then on, Blockchain and its associated cryptocurrencies have been explored (Satoshi N., 2008). (Mainelli M. and Smith M., 2015, P.3) described Blockchain as a secure online mutual distributed ledger providing "an electronic public transaction record of integrity without central ownership."

MIT Sloan assistant professor Christian Catalini, an expert in Blockchain technologies and cryptocurrency, further explained, "Such ledgers can contain different types of shared data, such as transaction records, attributes of transactions, credentials, or other pieces of information" (Church Z., 2017).

The adoption of Blockchain in the education industry provides the following benefits:

- Efficiency: It increases efficiency in evaluating the acquired competencies, especially concerning the related activities that lead to said competency;

- Integrity: It reduces fraud by enabling more reliable ways to protect and verify the credentials, thus increasing employers' confidence;

- Transparency: It provides transparency and indicates competencies acquired during the CBE; thus, employers understand its content and history, which enables the development of a proper training plan; and

- Ownership: It increases learners' control over their credentials, enabling a verifiable history of life-long learning, and gaining their confidence in their achievement.

In September 2020, a white paper-"Learning and Employment Records (LER) Progress and the Path Forward"-was published by the American Workforce Policy Advisory Board Digital Infrastructure Working Group. It is a concept of a learning and employment records system that contains verifiable information about a person's achievements using Blockchain technology (White paper by The American Workforce Policy Advisory Board Digital Infrastructure Working Group, September 2020, P.5). That is why the Blockchain will "likely remove the need for educational organizations to validate credentials" (Grech A. and Camilleri A., 2017, P.9).

There are also other immersive technologies such as augmented reality (AR), virtual reality (VR), and mixed reality (a combination of $\mathrm{AR}$ and VR) in applied education. These are increasingly becoming popular to virtualize 
practical-based activities and support online CBE. These have transformed education into an immersive experience as compared to the passive learning in the past.

\section{Research Goal}

It is evident from the lack of scholarly articles on the topic of digital CBE that its features must be explored to promote more opportunities to support all aspects of CBE: graduating professionals can join industries in less time and employers are supported to select and match the candidates with their vacancies by analyzing candidates' skills and competencies.

Course transcripts are written according to the curriculum subjects where the course learning outcomes do not directly make sense to employers; however, LEOs will clearly demonstrate the skills and competencies acquired by the students during their study. In this research, the proposed system was analyzed to identify its development requirements, the required changes to curricula, the intended LEOs, the new assessment tools, the new mapping with the learning activities, and the expected impact on universities and employers. The proposed digital CBE will build more reliable connections between the applied universities and industries through the development of competency-based micro-credentials, which can play a key role in enabling flexible workplace delivery.

In sum, this study aimed to answer the following research questions:

- How do we create and implement an effective alignment of the curriculum, learning outcomes and activities, and assessment tools with competencies under the proposed digital CBE system?

-What is the technology tool that can mostly fit the requirements of the digital CBE system?

- How do we contribute to the development of digital CBE to serve applied education?

- How do we effectively evaluate the achievement of the LEOs and the proposed competency-based micro-credentials to be presented to employers?

\section{Discussions}

\subsection{Innovating Academic Programs to Meet the Technological Requirements of Digital CBE}

It is essential before developing a new application to digitize CBE that we review the current CBE system and update the structure of the academic programs according to our current objective. This objective requires adding another mapping layer to link the learning activates with the qualification framework (knowledge, skills, and competencies) and design relevant assessment tools for these activities to measure the LEOs. These assessments should include standard tests, assignment grades, portfolios, rubrics based on evidence, observations of learners' behavior, and student self-assessment. The CBE system requires a redefinition of the relationship between education, experience, and employment, hence it is recommended to adopt an enhanced program advisory system to assure the achievement of optimal LEOs and produce graduates equipped with the latest skills and competencies needed by the industry.

\subsubsection{The Development of LEOs}

Learning in applied education stimulates the development of an enquiring, analytical, and creative approach, and it encourages the capabilities of self-judgment and critical self-awareness. Signature learning experience is an approach to applied education in which effective learning environments are developed in studios, workshops, production units, and computer labs (Buss D. and Gretton T., 2002).

Normally, applied higher education institutions (AHEIs) adopt a learning outcome-based (student-centered) approach in preference to an aims-and-objectives (teacher-centered) approach. The major challenge for such institutions is to define learning in specific measurable cognitive outcomes, while a signature learning experience approach will work perfectly in this regard.

Previous studies found that the most effective models of outcome-based learning followed a competency-based learning approach, which guides students to provide practical evidence of their skill-based learning. This is appropriate, as applied practice involves the exploration and development of ideas through a range of creative skills and the application of technical knowledge. For instance, if an outcome requires students to explain and evaluate a concept, then students can successfully achieve this by implementing the theories learned while providing practical evidence that will be captured and archived by the Blockchain technological tool. The LEOs in CBE must be developed as per the following criteria presented in Figure 2 along with examples of learning outcomes in Table 1. 


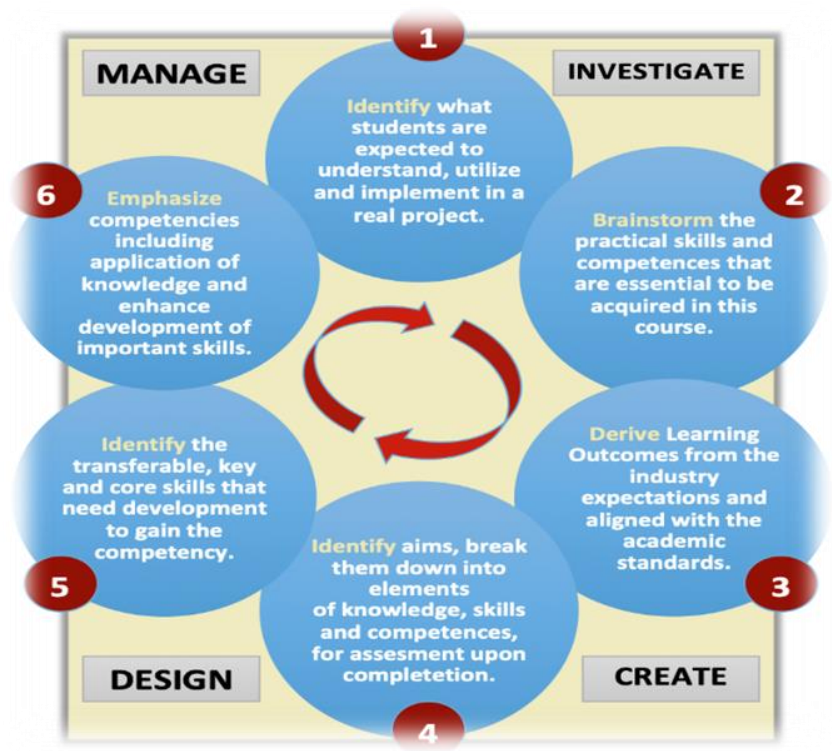

Figure 2. Learning experience outcome development criteria cycle

Table 1. Learning outcomes development criteria and learning experience outcome examples

No. Learning outcome development criterion

- Identify not only what students are expected to understand but also what

1. they should utilize and implement in a real project

- Reflect on the practical skills and

2. competencies that are essential to acquire in this course

- Reflect industry expectations and

3. align with academic standards

- Apply exactly what it aims to

4. accomplish once it is achieved

- Break down skills and competencies into measurable elements of knowledge that can be assessed upon completion

- Identify the transferable, key, and core activates that should be conducted to gain the competency

- Master competencies that include the

6. application of knowledge and enhance the development of important skills
Learning experience outcome example(s)

- Investigate and define a problem, identify Environmental Health and Safety, sustainability requirements, and risk assessment issues. Build comprehensive knowledge and understand practical activities and methodologies while applying and adapting them in unfamiliar situations

- Ability to create innovative approaches, systems, components, or processes to fulfill the needs and use creativity to establish innovative and practical solutions

- Understand industry and user needs and consider their requirements such as durability and aesthetics

- Synthesis materials and manage applicability, cost, and sustainability drivers

- Effectively use the latest technology to create an innovative solution

- Communicate the innovative solution into detailed specifications of the final products.

- Apply all aspects of the problem, including production, operation, maintenance, and disposal

- Manage the practical process and achieve the following competencies (sample from engineering design):

- Practice deciding how to arrange all the individual parts into a product that satisfies users' needs

○ Tracking the product's comfortability and functionality.

$\circ$ Reduce friction in the final product design 


\subsubsection{The Development of the CBE Curriculum}

Although a competency-based approach is a type of outcome-based education, it has precisely considered the activities and processes impeded in the curriculum and organized a curriculum with skills and competencies as outcomes in mind. The need to develop a hands-on curriculum emerges because of expectations and pressures to ensure that graduates acquire the skills and competencies required for the global knowledge economy. Applied education combines "knowing," "doing," and a skill-based profession-moving away from the traditional rules of thumb to the application of theory and techniques, which ultimately reflects the need for applying the new approach of CBE which is mapped backward from the desired competencies chosen earlier.

According to Shimizu R. (2013), accreditation standards in applied programs must be updated according to the consequences of implantation of the new competency-based approach, as applied education currently is misjudged as a subject that purely depends on practical know-how and creativity rather than conceptual knowledge (Ghonim A.and Ashor S., 2017).

Subsequently, in an applied curriculum, there is a need to incorporate new forms of visual literacy and new competencies into the curriculum along with experiential learning opportunities addressing abilities and skills. Once the curriculum has been developed to fit the CBE approach, faculty members should incorporate the relevant practical activates into the courses to improve students' ability to demonstrate the intended LEOs. Through its development, the new curriculum will achieve synthesis and integration of knowledge, skills, and competencies in measurable forms.

Successful implementation of the competency-based approach to design curricula will require the following:

- Curricula must ensure that all graduates have mastered the essential skills and are competent in their discipline;

- Curricula must emphasize competence and student attainment more than the duration of the education;

- Curricula must assist students to be more engaged in practical-based education and advance their skills and competencies by the impeded practices; and

- Curricula must explicitly design activities and instructional tools appropriate to the required competencies and their components.

Blockchain is capable of capturing the activities that have been mapped with the competencies. These activities are scored (or rated) and combined to calculate the average grade (or rating) of each competency of each individual. To further illustrate these recommendations, we take the example of an applied program to explain the drill-down capability of Blockchain to conclude an individual's detailed competency level.

Competencies are developed not only in the entire program journey, but in different levels of activities that improve and mature a competency. The following teaching activities illustrate how to equip students with skills and competencies:

- Inspire play-based learning;

- Break down LEOs into smaller, coordinated activity pieces;

- Provide a safe environment for learning activities;

- Advance a growth mindset;

- Adopt activities reflecting reasoning and analysis;

- Provide appropriate activity challenges; and

- Utilize a hands-on training approach 


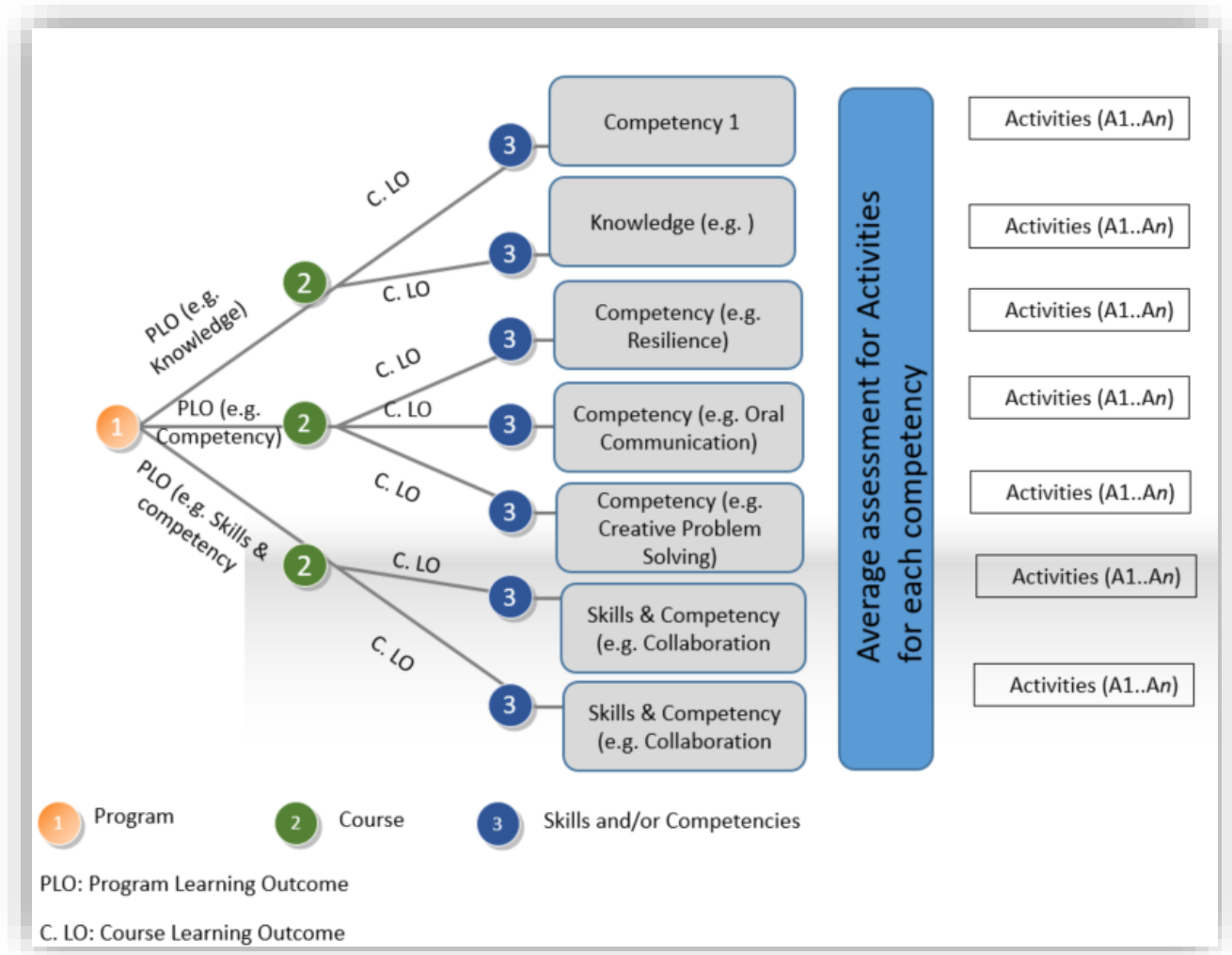

Figure 3. The proposed drill-down concept of Blockchain application in CBE.

The recommended drill-down approach to reach the LEOs and competency-based strengths and weaknesses is illustrated in Figure 3 which are mapped with relevant activities to guide the faculty members in updating the curriculum structure and learning outcomes accordingly.

\subsubsection{Productive CBE Assessment Process}

"Assessment should be criterion-based, work-based where possible, and explicate what students are expected to learn and measure student attainment of the LEOs. Therefore assessment is the way instructors and students can establish whether each of the LEOs has been met" (Ehmann D., 2005). According to Ehmann, there is a direct relationship between the processes, as much as the product, and students' participation in the practical activities. More specifically, student-centered learning and a productive assessment process, fostering deep experiential learning, motivation, and confidence in students, are correlated (Çıkış Ş. and Çil E., 2009).

Regular learning outcomes might require students to demonstrate that they can write a report. Indeed most graduates should be capable of this; however, in a competency-based approach, the application of the assessment criteria can determine the level of performance, innovation, and the achievement upon which the student can build in later projects.

This productive assessment provides students with effective feedback during a project (formative feedback) and measures their overall achievement (summative feedback), which must be integrated into their academic experiences. Therefore, assessment should be considered as a learning opportunity (Davies A., 2000), in which the proposed digital system can trace, record, and accumulate the scores to present the level of skill and competences achieved.

One of the main features of CBE is that its assessment is not based on formal examinations; rather, it assesses students' applications of knowledge, skills, and acquired competencies through specific activities and projects. Hence, the main target of productive assessment in CBE is to review or analysis the accomplishment of the LEOs and focusing on measuring the ability to apply relevant knowledge, skills, and processes for solving open-ended problems and workplace case studies (Hernández-de-Menéndez, M. and Morales-Menendez, R., 2016).

Productive assessment in CBE should be robust and multi-faceted and fit into the "authentic" type, which is reliable and relevant to the nature of the applied and innovation practices rather than "standardized" or "alternative" measures. Thus, the following issues should be considered when designing assessment tools: 
- Assure that students have an effective way of demonstrating that they have utilized the range of skills and knowledge required in learning outcomes and provide the evidence of achievement (project, prototype, etc.);

- Follow tracking methodology assesses achievement of LEOs through practical activities and relevant competencies per unit while also referencing the relevant criterion;

- The LEOs assessment tools are mapped with the competence to be measured through the relevant activities;

- The use of an assessment scheme encourages students to become more creative and independent and facilitates the development of their competencies; and

- Constitute a form of future learning opportunities, identifying and supporting students' needs, and draw a roadmap to become professional designers.

\subsubsection{Utilizing Blockchain in the Development of Digital CBE}

We propose the enablement of Blockchain in CBE—not only concerning applicants' credentials and transcripts, but also drilled-down to the level of the learning activities that build the skills and competencies and present their assessment results to the employers.

Recently, applied universities are working toward developing a professional competency model that is moving away from teaching subjects. Instead, some competency models are structured around workplace competencies. It is proposed to embed Blockchain technology, in which the skills and competencies are assessed through the learning activities.

As explained above and to achieve a certain competency, there are associated activities that are performed, mapped with each skill and competency, and evaluated through defined assessment tools. In the proposed application, Blockchain will trace the assessment for each activity; then, all relevant activities are summarized or averaged. The percentage of the assessment of the activities that lead to competency can be tracked and referred to as the level of the acquired competency for each student.

The key features of using the latest technology tools such as Blockchain to develop applications are to trace, capture, and analyze all assessment outcomes and generate an overall result concerning students' LEO for each skill and competency. Establishing a Blockchain platform will enable employers to review the level of applicants' competencies through the calculated average of the accomplished activities, designed to acquire each competency. This resulting average for each competency identifies the strengths and weaknesses of each individual. Consequently, employers can properly select the right individual for the right job, and they can precisely identify and design the required personalized professional development and training needs for each individual.

The proposed system digitalizes CBE to develop and integrate entrepreneurship and innovation LEOs in academic curricula. Moreover, the system will assist workplaces and individuals in identifying and assessing innovation skills to determine congruency between their innovation skills capacities with their innovation needs. The development of innovation and entrepreneurial learning outcomes specific to each program area and/or discipline is vital.

The system will facilitate a comprehensive program review process to identify appropriate learning activities that prepare graduates in professions and trades that have high rates of self-employment and/or have high rates of innovation skills required in the workplace. There are several appropriate and relevant learning activities that are ideal to focus on the integration of innovation and entrepreneurial and workplace LEOs.

The Blockchain technological tool will provide evidence of meeting LEOs through the well-designed, reliable, and valid assessed activities such as the creation of a business plan, which would include all the preceding information for a start-up business in the respective industry sector. The new system will assure graduates are provided with the competencies to start a business upon completion of their respective program of study or to provide innovation-ready skills in any workplace environment.

Blockchain is associated with digital badges to provide a powerful tool for identifying and validating the rich array of students' skills, knowledge, and competencies. A digital badge is issued for each skill or competence and outlines the learning activities relevant to it under the program and the level at which each skill or competence is achieved. Badges are embedded with metadata, which provides details of what the recipient had to do to earn the badge. The badges are hosted at a global platform which houses each competency-based credential and their consistent data from which graduates can share their achievements, allowing employers to verify credentials simply.

The system will generate micro-credentials earned by indicating skills and competencies, via an e-portfolio of evidence, created through learning activates. All micro-credentials will be delivered on the digital badges and have a 
clearly defined purpose of achieving verified improvement in instructional practice, thus providing the building blocks for professional growth. Learning activities practiced in different levels of the degree will be scored, and the skills and competencies will be measured through the relevant assessment tools.

The individual can then be granted a new competency-based transcript that has been validated by a third-party to be provided to employers and other stakeholders. Employers can use these transcripts to benchmark applicants in a more advanced way as compared to traditional degrees or course transcripts. They can also use the new competence-based transcripts to invest in their workforce and design personalized professional development plans for employees. The proposed system hence provides employers with more transparency; they will know who they need to hire, which will foster more effective communication with AHEIs.

\subsubsection{System Analysis}

To illustrate how the alignment of a CLO to a PLO be captured in a system, the Figure 4a \& figure 4b, illustrates the analysis of a digital CBE system in an applied education setting.

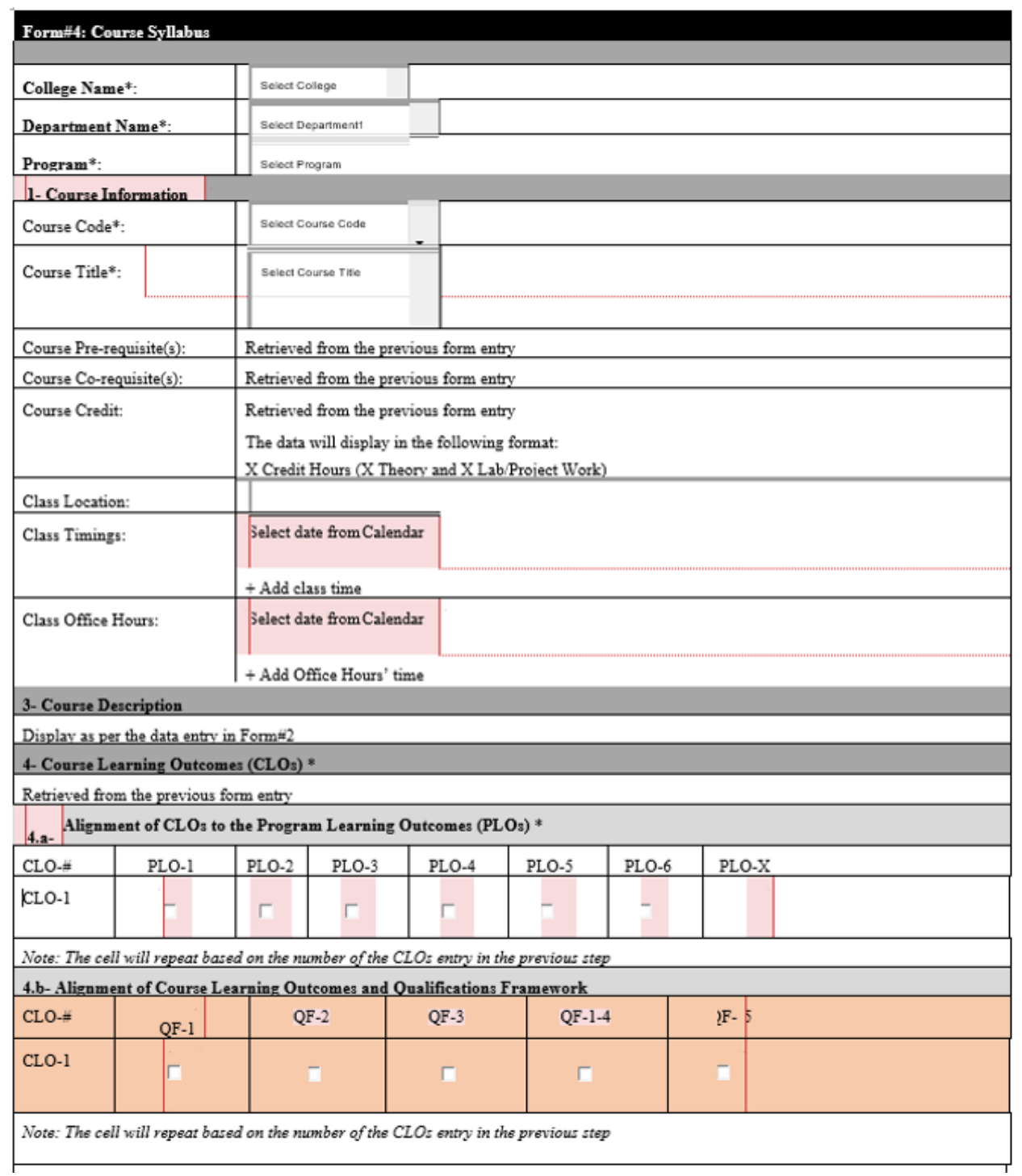

Figure 4a. System analysis and competence mapping in level 1 (PLO) 


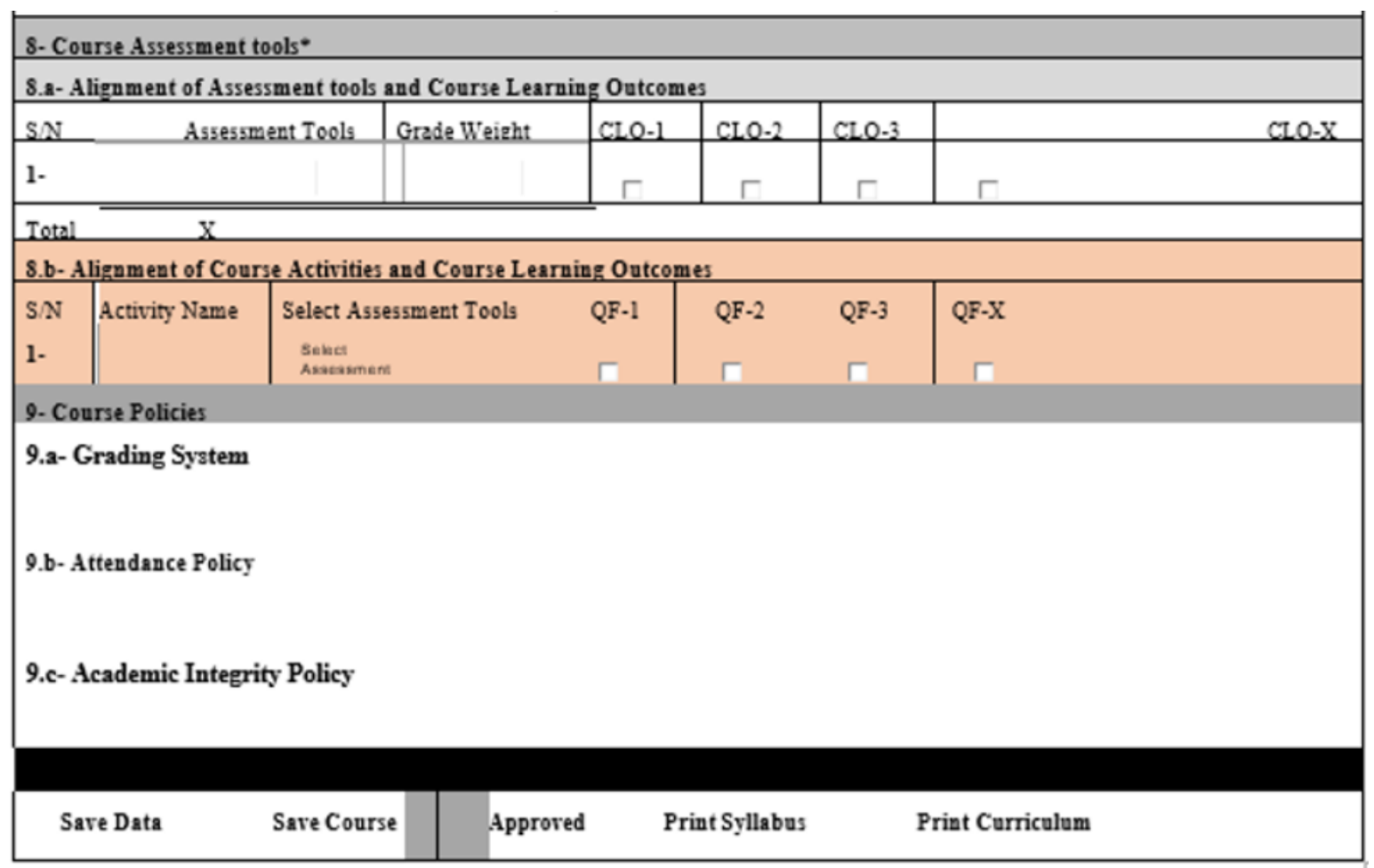

Figure 5b. System analysis and competence mapping in different levels 2 (CLO)

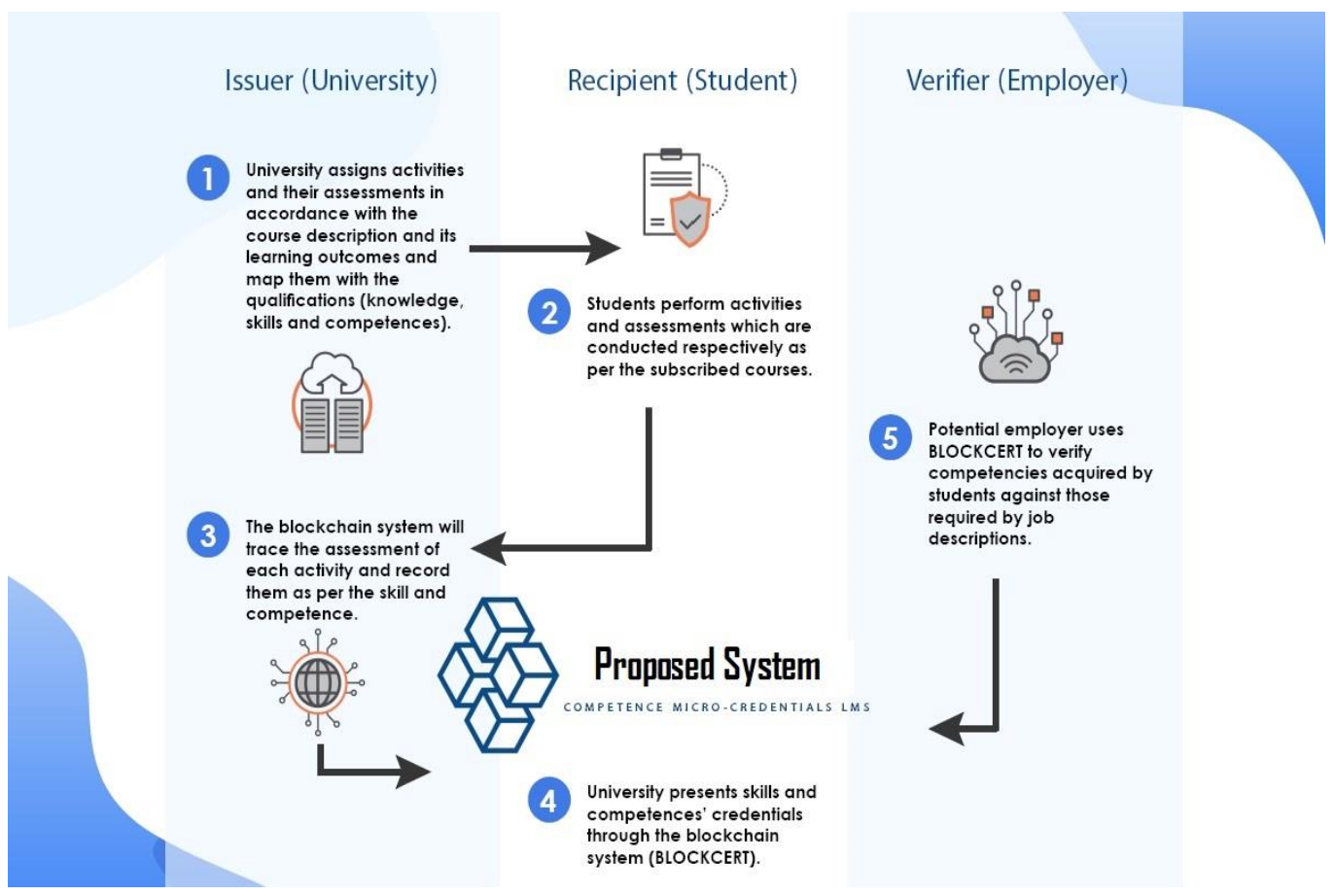

Figure 6. System design and stakeholders

The proposed system in Figure 5 describes how the current use cases in blockchain such as the issuance of digital credentials can be further enhanced to enable the stakeholders; to create and drill-down by the issuer (university), presented by the student, and verified by the employer. 

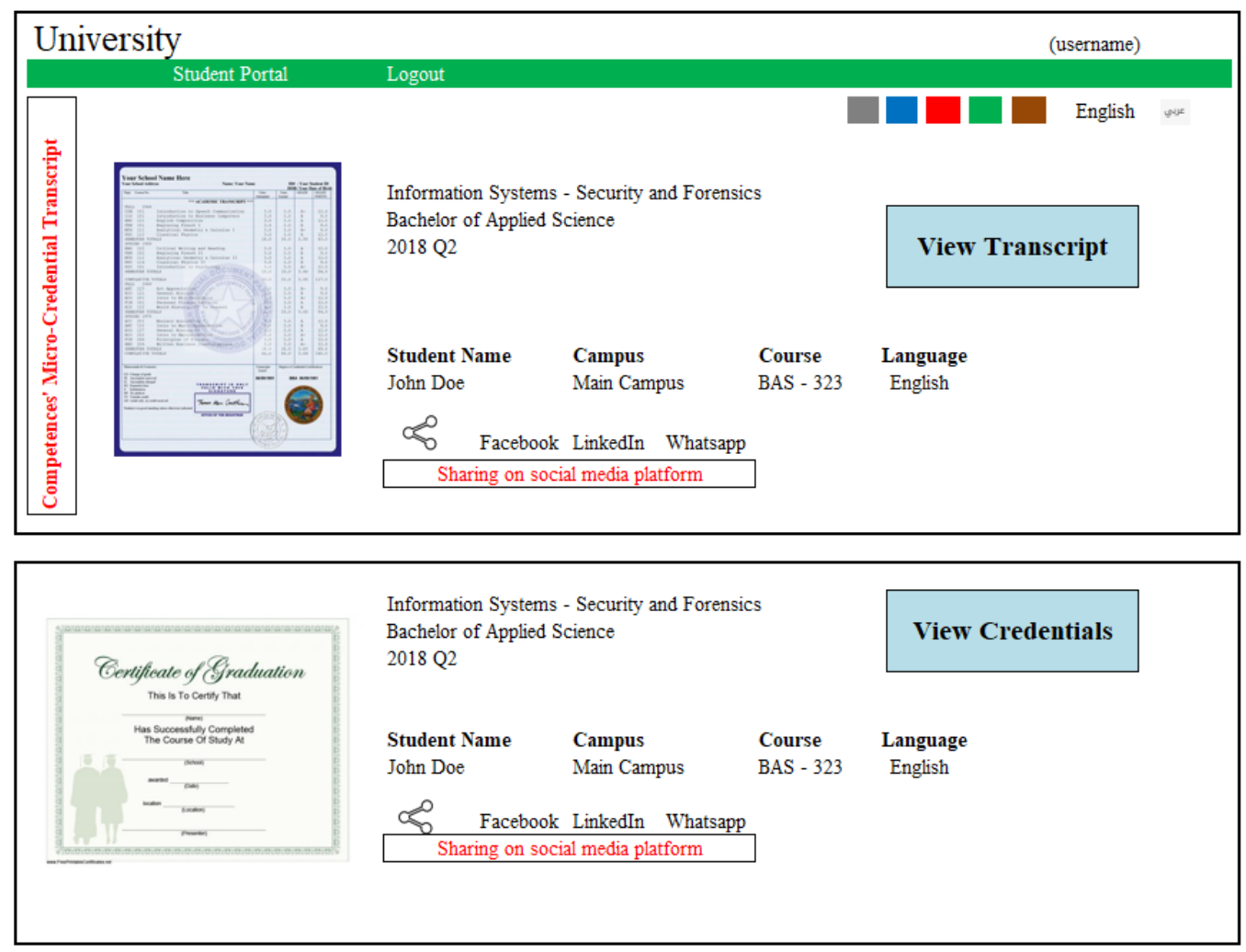

Figure 7. Portal Interface

\subsubsection{Student Portal}

The student portal with enhanced capabilities using the blockchain can provide the confidence to the students of the ownership of their own credentials.

- Graduates and alumni can view their competency-based e-credentials and details about who has verified their certificate;

- E-credentials can be accessed at the Student Portal's Certificates menu

- Digital certificates can be shared on social media platforms like WhatsApp, Facebook, LinkedIn, etc.

- The credential verification process will be available on the Blockchain platform, providing instant verification by the employers through self-service; and

- After registration, the user requires verification through the registered email address; then they can login to the verification portal (Figure 6)

\subsubsection{Competency-Based Micro-Credentials Portal}

Competency-based micro-credentials application on a Blockchain solution, can securely create, maintain, and verify the skill- and competency-related credentials via web and mobile applications. The competency-based micro-credentials portal will be accessed by students and third-party organizations (Figure 7). 


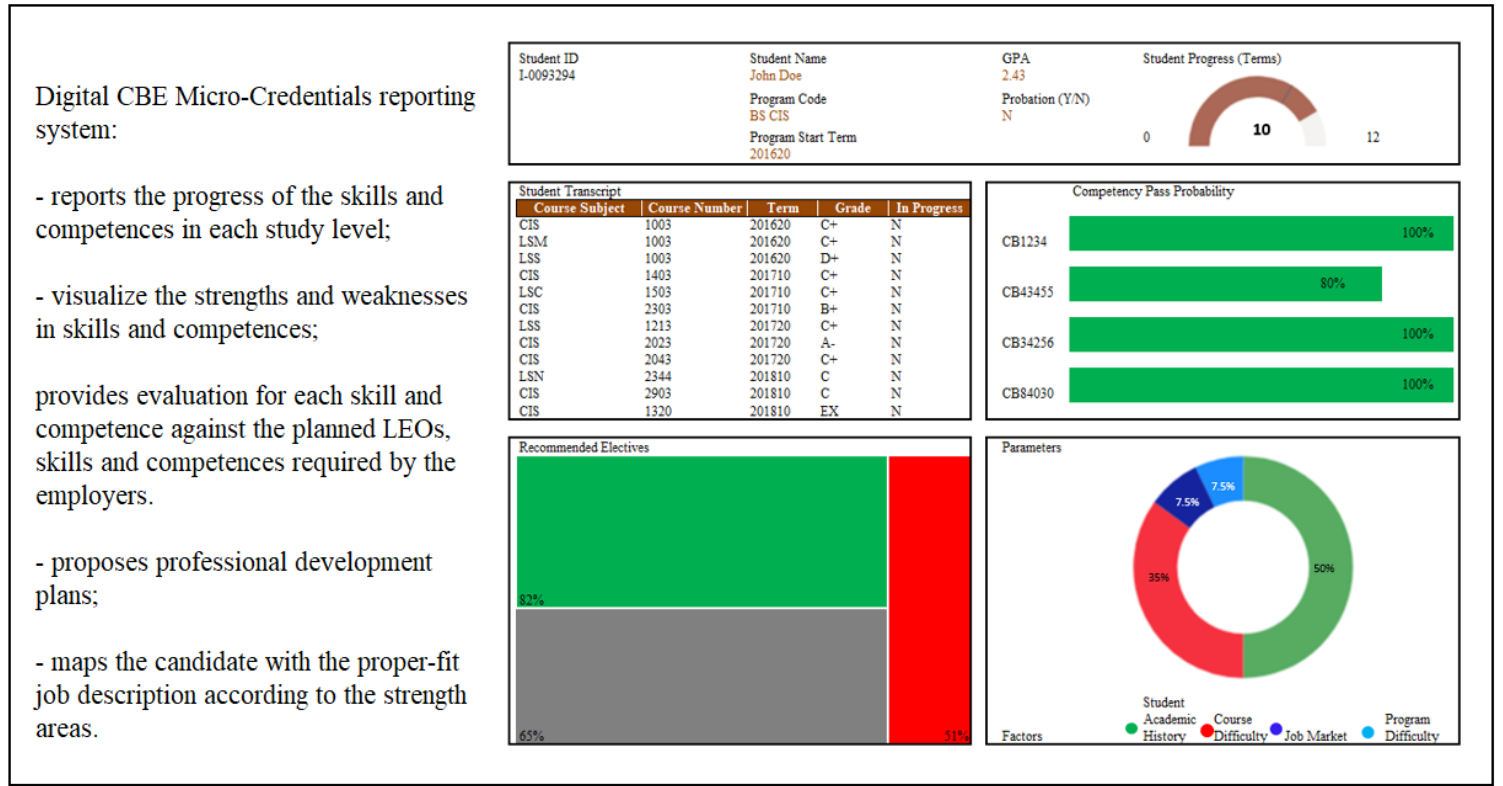

Figure 8. Reporting system

\section{Conclusion}

Digital CBE and competencies micro-credentials are now highly demanded in applied education, mainly to strengthen the relationship with the industry and update the employers with the strengths and weakness of the potential employees. These new outcomes from the applied HEIs will formalize its innovation and provide an evidence-based learning experience that has been designed per the feedback provided by the industry advisory board and the latest trends required by the industry. Blockchain is the main technological tool used to trace the achievement of the intended LEOs and provide a new kind of skill- and competency-based micro-credential transcript. The proposed system will require an additional mapping level to link the practical activities and learning assessment with the qualification framework to enable Blockchain to trace the grades in all activity assessments relevant to each skill and competency and provide a detailed report for each of them, thus identifying the strength and weakness areas from different levels.

Compared to the regular CBE, the implementation of the suggested digital CBE system differs because of its innovative concept, additional mapping level with the qualification framework, and the utilization of Blockchain to enhance the outcomes of the CBE approach in AHEI. This would involve the exploration and development of ideas to improve the LEOs, curriculum, and assessment tools used in applied education.

In sum, this study introduced a new technological system, spread awareness about digital CBE, and developed a framework for the implementation of competency-based micro-credential transcripts. Nevertheless, the authors also observed that digital CBE can do more by enhancing the outcomes of combining "knowing," "doing," and skill-based professions, as well as updating their standards and practices - thus moving away from the traditional rules of thumb to the application of theory and techniques, which ultimately enhances the efficiency of CBE in applied education.

We further recommend continuing this research and study the development of specific standards and measures for presenting skills and competencies to the industry, and all universities and Higher Education Institutions (HEIs) through a global system be aligned with the standard. This includes applying the standards to digitalization, but not limited to the blockchain, which we used as a model in this paper. This may extend to digital badges, micro-credentials and artificial intelligence.

\section{References}

Ally, M., \& Wark, N. (2019). Learning for Sustainable Development in the Fourth Industrial Revolution. Pan-Commonwealth Forum, 9(PCF9), 2019[215].

Buss, D., \& Gretton, T. (2002). Design benchmark statement. Gloucester: Quality Assurance Agency.

Church Zach (2017). Blockchain, explained. MIT Initiative on Digital Economy (blog). http://ide.mit.edu/news-blog/blog/blockchain-explained, accessed on 12-November-2020 
Çıkış, Ş., \& Çil, E. (2009). Problematization of assessment in the architectural design education: first year as a case study. Procedia-Social and Behavioral Sciences, 1(1), 2103-2110. https://doi.org/10.1016/j.sbspro.2009.01.369

Clark, F. W. (1976). Characteristics of the competency-based curriculum. In: Arkava ML and Brennen EC (eds) Competency-based education for social work: evaluation and curriculum issues. New York, NY: Council on Social Work Education, 22-46.

Davies, A. (2000). Effective assessment in art and design: Writing learning outcomes and assessment criteria in art and design (pp. 1-15). London: Centre for Learning and Teaching in Art and Design, University of the Arts London.

Ehmann, D. (2005). Using assessment to engage graphic design students in their learning experience. Making a Difference: Evaluations and Assessment Conference, Sydney, Australia, 30 November-1 December.

Gartner Paper (2020). Assessing online learning platforms for technical skills development, ID G00463821 (accessible for Gartner account holders).

Ghonim, A. S., \& Ashour, S. (2017). The quest for regional accreditation of art and design education in the Arab Countries. Cogent Art \& Humanities Journal, 4(1). https://doi.org/10.1080/23311983.2017.1361639

Goodchild, L. (2007). History of higher education in the United States. Boston, MA: Pearson, 36-48.

Grant, G., Elbow, P., Ewens, T., Gamson, Z., Kohli, W., Neumann, W., \& Riesman, D. (1979). On competence: a critical analysis of competency-based reforms in higher education. San Francisco, CA: Josey-Bass Publishing.

Grech, A., \& Camilleri, A. (2017). Blockchain in education. DOI: 10.2760/60649.

Hernández-de- Menéndez, M., \& Morales-Menendez, R. (2016). Current Trends in Competency Based Education. World Journal of Engineering and Technology, 4, 193-199. https://doi.org/10.4236/wjet.2016.43D023

J. Gervais (2016). The operational definition of competency-based education. The Journal of Competency-based Education, 1(2), 98-106. https://doi.org/10.1002/cbe2.1011

Kelchen, R. (2015). The landscape of competency-based education. Washington, D.C.: American Enterprise Institute.

Klein-Collins, R. (2012). Competency-based degree programs in the U.S. postsecondary credentials for measurable student learning and performance. Chicago, IL: Council for Adult and Experiential Learning.

Klein-Collins, R. (2013). Sharpening our focus on learning: the rise of competency-based approaches to degree completion (no. 20). National Institute for Learning Outcomes Assessment. https://doi.org/10.1002/ace.20073

Leuba, M. (2015). Competency-based education: technology challenges and opportunities. Educause Review, 12.

Mainelli, M., \& Smith, M. (2017). Sharing ledgers for sharing economies: an exploration of mutual Distributed ledgers (aka blockchain technology). Journal of Financial Perspectives, 3(3).

Michelle Weise (2014). Got skills? Why online competency-based education is the disruptive innovation for higher education. Educause Review, 49(6), 27-35.

Nakamoto, S. (2008). Bitcoin: a peer-to-peer electronic cash system. Satoshi Nakamoto Institute.

Perkin, H. (2007). History of universities. Boston, MA: Pearson, 6-35.

Shimizu, R. (2013). Does accreditation matter for art \& design schools in Canada? College Quarterly, 16(1), 1-18.

Spady, W. G. (1977). Competency-based education: a bandwagon in search of a definition. Educational Researcher, 6(1), 9-14. https://doi.org/10.3102/0013189X006001009

The American Workforce Policy Advisory Board Digital Infrastructure Working Group (2020). a white paper "Learning and Employment Records (LER) Progress and the Path Forward", pp. 5, https://www.commerce.gov/sites/default/files/2020-09/LERwhitepaper09222020.pdf

Williams, P. (2018). Does competency-based education with Blockchain signal a new mission for universities? Journal of Higher Education Policy and Management, 4l(1), 104-117. https://doi.org/10.1080/1360080X.2018.1520491

World Economic Forum (2015). New vision for education. What are the 21st-century skills every student needs? https://doi.org/10.1093/oso/9780197529003.003.0002

\section{Copyrights}

Copyright for this article is retained by the author(s), with first publication rights granted to the journal.

This is an open-access article distributed under the terms and conditions of the Creative Commons Attribution license (http://creativecommons.org/licenses/by/4.0/). 